\title{
So what shall we do about assertive community treatment?
}

\author{
SONIA JOHNSON
}

\begin{abstract}
The usefulness of Assertive Community Treatment (ACT) in European countries with well-developed community care systems has been disputed, despite considerable relevant literature. This paper aims to assess reasons for and against implementing ACT in such countries. ACT may not be useful where generic community mental health teams are not yet well-developed, where admission rates are already low, or where an alternative model based on close integration of a full range of types of care is in place. Good reasons for introducing ACT include listening to patients' preferences, being able to monitor a high risk group of patients more successfully, good staff satisfaction, and the potential for using ACT teams as a platform for delivering interventions for difficult to treat psychosis. The ACT model is more likely to thrive in future if a recovery orientation can be adopted.
\end{abstract}

\section{INTRODUCTION}

Clear-cut and consistent conclusions are not easily achieved in mental health services research, and within this field, Assertive Community Treatment (ACT) is especially notable for the very divergent views held by experts regarding its value and evidence base (Rosen $e t$ al., 2007; Burns et al., 2006; Burns, 2000; Tyrer, 2007; Smith \& Newton, 2007; Bond et al., 2001; Dixon, 2000). Thus an enthusiastic neophyte service planner, newly arrived at his or her desk in a regional office responsible for mental health service planning somewhere in Europe and eager to develop evidence-based policy, might legitimately be very unsure what they should do about ACT. Should it be the cornerstone of any effective community service, or are its benefits marginal, disputed and mostly applicable to US settings in which community mental health care is not otherwise well-developed? Is it a tried and tested, but still cutting edge, US flagship product or a bulky, culturally alien and ultimately insubstantial import with little to offer in a good publicly funded system? Is it the Apple Mac or the Big Mac of psychiatry?

My compatriots Professors Marshall and Burns describe sophisticated syntheses of the current evidence on Intensive Case Management and Assertive Community

Address for correspondence: Dr. S. Johnson, UCL, Department of Mental Health Sciences (Bloomsbury Campus) 67-73 Riding House Street, 2nd Floor, Charles Bell House, London WIW 7EJ (United Kingdom).

E-mail: s.johnson@ucl.ac.uk

Declaration of Interest: None.
Treatment in this edition of Epidemiologia e Psichiatria Sociale (Burns, 2008; Burns et al., 2007; Marshall, 2008). I have little to add to their analyses, but will instead try to provide some practical guidance and help to the bewildered service planner or senior clinician trying to decide whether ACT is of value in their local context. I will focus throughout this discussion on Europe as the context I know best and the region where the model is most contentious.

\section{WHY DO VIEWS DIFFER SO MUCH ABOUT ACT AND WHAT IS THE CURRENT STATE OF EVIDENCE?}

As Burns describes, the intense debate, with battle lines often drawn on either side of the Atlantic, about whether ACT is effective and where, may now be cooling somewhat, but there is still considerable divergence in expert views. Summarising recent reviews (Burns, 2008; Burns et al., 2007; Smith \& Newton, 2007; Marshall, 2008), there is a good basis for believing that ACT (and probably other forms of intensive case management) is generally preferred by patients to standard community team care based on larger caseloads, and that patients are less likely to drop out of care. Reductions in bed use have been achieved in some, but not all settings. Recent European trials have indicated improvements in treatment retention and satisfaction, but not lower bed use Killaspy et al., 2006; Sytema et al., 2007). No other improvements have been consistently found, and overall the evidence suggests that standard ACT does not produce benefits in important domains of outcome such as social functioning and quality of life. This is perhaps 
unsurprising given that standard ACT is probably best seen as a way of organising a team rather than as a specific treatment method: a range of treatment approaches is possible within this vehicle.

The recent meta-analysis conducted by Burns, Marshall and their colleagues (Burns, 2008; Marshall, 2008; Burns et al., 2007) is very helpful in that it moves debate about the divergence in findings on bed use away from cross-Atlantic mud-slinging about whether failures to show an effect on bed use are the result of poorly implemented ACT in Europe or poor control group services in the USA (Burns et al., 2001). Their analysis provides a means applicable in both Europe and the US of understanding variations in findings: ACT appears to make more impact on bed use where a team approach is properly implemented, and where there is a high baseline level of bed use. I have little to add to Burns' and Marshall's arguments regarding the importance of investigating control interventions and baseline service use patterns, and about the large amount of variation that develops among ACT teams even when all are intended to follow the same rather detailed governmental mandate, as in the UK (Wright et al., 2003a). The heterogeneity described in findings is not surprising when one considers how complex are the social and organisational processes involved in establishing and delivering ACT. Burns rightly expresses disappointment that we have progressed little in the past decade in giving clear descriptions of the content and context of both experimental and control services: a major factor in this is likely to be the lack of established and tested methods and measures for assessing the organisation and content of services (LloydEvans et al., 2007).

Given the apparent clarity of these findings from meta-analysis that ACT has fairly modest benefits, more apparent in some settings than in others, why does it continue to be advocated by some as a really crucial element in community-based care (Rosen et al., 2007)? One basis for differences in views between the US and Europe is likely to be historical. ACT and its precursors are very well-established in the US (Dixon, 2000), and in areas where mental health services are poorly resourced, such teams may be the main good quality community provision for people with severe mental illnesses (Drake \& Deegan, 2008). This contrasts with many European countries, in which ACT is the new kid on the block and sectorised Community Mental Health Teams (CMHTs) are the cornerstone of the service system, a tried and tested form of care that many European clinicians and service managers cannot imagine doing without. This is despite the fact that the evidence base for Europe's
CMHTs is arguably more shaky than that for the ACT teams that seem indispensable to US clinicians. The range of services included in any review of evidence will also affect the conclusions drawn. Recent UK reviewers have made a distinction between ACT services and intensive services that initiate care at the time of a crisis, thus excluding from reviews of ACT some of its most influential precursors, such as the pioneer services in Sydney and Madison, Wisconsin (Hoult et al., 1981; Stein \& Test, 1980). This exclusion seems sensible, as intensive home treatment in crises by itself reduces bed use (Johnson et al., 2005a, b; Glover et al., 2006). A more recent type of service that is mainly excluded by recent UK reviewers but included in North American and Australian discussions is ACT for specific populations, such as the homeless or people with comorbid substance misuse or early psychosis, and/or enhanced by specific interventions, such as supported employment. This again seems reasonable when trying to focus exclusively on the impact of ACT, but it results in exclusion of some recent trials in which positive results are reported for various specialised or enhanced forms of ACT (Rosen et al., 2007).

\section{WHEN IS AN ACT SERVICE NOT A GOOD IDEA?}

There are a number of questions a service planner should ask before introducing ACT to an area. Firstly, is the local service system at the right stage of development? In their discussion of the components needed to deliver balanced care in mental health systems at different stages of development and with varying levels of resources, Thornicroft and Tansella identify ACT as a specialist service model to be considered in well-resourced service systems where more generic basic building blocks such as community mental health teams (CMHTs) and long-term residential services are already in place (Thornicroft \& Tansella, 2004). It is likely to be a mistake to contemplate ACT introduction if these basic components are not established and adequately resourced, and it is also very undesirable for resources to be diverted to ACT and other more specialised services if this compromises the functioning of CMHTs and other generic secondary care services.

Secondly, is the problem that ACT is intended to resolve really present? The recent advocates of ACT argue cogently that the intended target group for ACT is a specific sub-group of people with severe mental illnesses who have high levels of need not met by less 
intensive forms of community-based service, resulting in poor service engagement and frequent admissions. Rates of admission vary greatly across Europe and are often found to be ten or more times greater in Northern European than in Mediterranean countries (Becker et al., 2002; Becker \& Kilian, 2006; Salvador-Carulla et al., 2005). In a country such as Spain where both current intensity of community service provision and admission rates are low compared to many northern neighbours (home visits are a rarity in some services (SalvadorCarulla et al., 2005)), the rationale for ACT is much less clear than in densely populated north European metropolitan areas with large numbers of 'revolving door' patients despite substantial community provision. Density of population is a related factor: in an area with low population density and morbidity, an ACT team may spend much of its time traveling and has limited opportunity to form links with local primary care and community services; this is likely to be a poor use of resources.

Finally, requiring the adoption of ACT in an area where it lacks support among local stakeholders, such as service managers, senior clinicians and service user groups, is difficult to justify in view of its rather modest evidence base. This applies especially if the area already has in place a different model of community service delivery that is established, results in a well-integrated service system with clear care pathways and good continuity of care, and attracts good local support. For example, in Italian catchment areas such as Verona or Trieste where comprehensive networks of community services based on principles of integrating all service functions are already in place and where admission rates are relatively low, there may not be a good rationale for ACT (Mezzina \& Vidoni, 1995; Lasalvia \& Ruggeri, 2007).

\section{WHAT GOOD REASONS ARE THERE FOR STARTING OR RETAINING ACT SERVICES?}

These caveats aside, there are a number of reasons why starting or maintaining an ACT service may be a good, or at least an acceptable, idea. First and most modestly, we have no reason to believe that ACT does any harm in most service contexts. Where significant difference have been found between ACT and other service models, they almost uniformly favour ACT, and costs are not generally found to be much higher. Thus while benefits may be modest, the caveats already discussed aside, there is no reason to believe that this service model damages the health or well-being of patients, staff or carers.
Secondly, people do seem to like ACT (Killaspy, 2007), or at least to like it better than standard care. Given that it specifically targets those most alienated from the mental health system, even the relatively small differences found in service user satisfaction are impressive. The current consensus, though arguably one that influences rhetoric much more than practice, is that service users' views should be at the centre of mental health service development. Even though user involvement has not been central to the development of $\mathrm{ACT}$, the preference expressed for this type of care over standard care is important if we are to listen to users' voices more than in the past.

Thirdly, there is also evidence that engagement with services is improved by ACT, and, like client satisfaction, this is of some value in itself. ACT targets a group who are highly socially excluded and at relatively high risk of committing a violent act (Priebe et al., 2003), and the UK introduction of the model was in part a response to the observation that such patients often 'slipped through the net'. Greater engagement is likely to facilitate monitoring such patients, and may thus be reassuring to all and even helpful in avoiding adverse incidents.

Fourthly, it remains possible that there are positive outcomes even in a European setting that are as yet unobserved. Limited resources for research and pressures on academics mean that most studies have been of rather short duration: thus it remains possible that, with prolonged contact with an ACT team, good engagement may eventually bear fruit. Though they may not improve outcomes in themselves, sustained contact and positive attitudes to the service may at least create the conditions for effective intervention, and we still do not know whether 5 or 10 or 20 years of ACT may reap clearer benefits for outcomes than the shorter durations tested in most studies so far. Some (though not all) of the studies that have examined whether better therapeutic relationships result in better outcomes in severe mental illness have had positive results (Calsyn $\mathrm{et} \mathrm{al.,} \mathrm{2006),} \mathrm{one} \mathrm{UK} \mathrm{study} \mathrm{suggesting} \mathrm{that}$ at least for new ACT clients, a good therapeutic alliance was associate with reduced hospitalisation (Fakhoury et al., 2007). Larger-scale studies might also reveal benefits in terms of rarer outcomes: for example, we know little about the effects of ACT on violent incidents.

Fifthly, again contrary to some predictions on its UK introduction that it would prove hard to sustain because of staff burnout, mental health staff appear to be happy to work in ACT services. Taking a team approach to the relatively challenging patients served by ACT seems to be particularly valued (Billings et al., 2003), and staff implementing it appear to feel positive about the ACT approach (Tyrer et al., 2007). This is likely to contribute 
to the fact that ACT has been sustained in many of the European centres where it has been introduced.

Finally, Marshall and Burns have in the accompanying editorials made a persuasive case that ACT is unlikely to change outcomes because it is a way of organising care and a platform for interventions, rather than itself being a specific treatment. However, the value of ACT may prove to be as a good platform for such specific treatments. ACT teams bring together many of the local patients with severe and treatment-resistant psychotic illnesses within one relatively well-resourced specialist team: this creates opportunities for development, testing and dissemination of specific treatments for treatmentresistant psychosis and for associated comorbidities.

\section{WHAT NEXT?}

Thus as the evidence stands, introduction or maintenance of an ACT team within a European catchment area service system is a reasonable step, in the absence of the contra-indications discussed, though it is not a step for which the evidence is compelling. Making the model mandatory, as currently in the UK, is rather more contentious, though it might be argued that a convincing alternative strategy for managing severely ill and difficult to engage patients in the community needs to be in place if ACT is not adopted. However, the argument for rigorous adherence to a particular model is not clear enough, at least in a European context, for it to be wrong to adapt ACT to local contexts, populations and ways of working. Recent European reports of ACT variants such as ACT integrated with community mental health teams in the Netherlands (van Veldhuizen, 2007) and a time-limited adaptation of ACT intended to achieve patient engagement as a starting point for further treatment in Switzerland (Bonsack et al., 2005) are examples of such adaptations that may be an appropriate fit for local contexts.

There are potentially promising directions for the further development and testing of this model. Firstly, the longer term outcomes remain worth investigating, as discussed. Secondly, as with other 'functional' teams, it would be worth investigating the impact of ACT introduction on service systems as a whole: does it relieve pressure on potentially hard-pressed service components such as community mental health teams, or does it divert resources, staff and interest from less specialised teams in a way that impairs their functioning? Thirdly, as discussed, ACT services present an opportunity as a platform for testing and delivery of specialist treatments for people with difficult to manage psychotic illnesses. One aspect of model fidelity on which UK services do not generally score highly is availability of specialist dual diagnosis and vocational workers (Wright et al., 2003; Fiander et al., 2003). Rosen and colleagues argue that ACT teams function best when they deliver a full range of interventions for vocational and comorbidity needs: it may indeed be that these specific interventions within the framework of ACT help make certain services appear successful. As already discussed, specialised forms of ACT or ACT integrated with other interventions such as supported employment (Gold et al., 2006) are increasingly prevalent in the US (Drake \& Deegan, 2008), and some may prove also to have benefits in European settings. Indeed, two European trials of ACT modifications for early psychosis have already demonstrated greater benefits than any of the European trials of standard ACT or intensive case management (Garety et al., 2006; Craig et al., 2004; Petersen et al., 2005). Finally, another potential way in which ACT may develop is in adopting a focus on recovery. Recovery is now conceptualised as an approach that emphasises service users' choices, aspirations and strengths and aims to collaborate with them in establishing a life which is fulfilling to them, even if symptoms do not remit. ACT services, while not explicitly focused on a recovery approach in their standard form, are relatively well placed to adopt this (Care Service Improvement Partnership et al., 2007). ACT is compatible with a recovery approach in that it emphasises flexibility, attention to social problems and functioning, and working with patients on their own terms and on their own ground. Its roots are nonetheless in an essentially a clinician-driven approach, in which an aim is to dissuade service users from choosing to opt out of conventional mental health care, so that trying to adapt it to a recovery approach is likely to result in some tensions (Salyers \& Tsemberis, 2007; Drake \& Deegan, 2008). If such adaptation can be achieved, it is likely to help ACT to survive and thrive in future.

\section{REFERENCES}

Becker T. \& Kilian R. (2006). Psychiatric services for people with severe mental illness across western Europe: what can be generalized from current knowledge about differences in provision, costs and outcomes of mental health care? Acta Psychiatrica Scandinavica 113, 9-16.

Becker T., Ismann S., Knudsen H.C., Martiny K., Amaddeo F. Herran A., Knapp M., Schene A.H., Tansella M., Thornicroft G. \& Vazquez-Barquero J.L. (2002). Provision of services for people with schizophrenia in five European regions. Social Psychiatry \& Psychiatric Epidemiology 37(10), 465-474.

Billings J., Johnson S., Bebbington P., Greaves A., Priebe S., Muijen M., Ryrie I., Watts J., White I. \& Wright C. (2003). Assertive outreach 


\section{S. Johnson}

teams in London: Staff experiences and perceptions - Pan-London Assertive Outreach Study, Part 2. British Joumal of Psychiatry 183, 139-147.

Bond G.R., Drake R.E., Mueser K.T. \& Latimer E. (2001). Assertive community treatment for people with severe mental illness: critical ingredients and impact on patients. Disease Management and Health Outcomes 9, 141-159.

Bonsack C., Adam L., Haefliger T., Besson J. \& Conus P. (2005). Difficult-to-engage patients: A specific target for time-limited assertive outreach in a Swiss setting. Canadian Joumal of Psychiatry-Revue Canadienne de Psychiatrie 50, 845-850.

Burns T. (2000). Models of community treatments in schizophrenia: do they travel? Acta Psychiatrica Scandinavica, Supplementum No. $102,11-14$.

Burns T. (2008). Case management and assertive community treatment: what is the difference? Epidemiologia e Psichiatria Sociale 17, 99-105.

Burns T., Fioritti A., Holloway F., Malm U. \& Roessler W. (2001). Case management and assertive community treatment in Europe. Psychiatric Services 52, 631-636.

Burns T., Catty J. \& Wright C. (2006). Deconstructing home-based care for mental illness: can one identify the effective ingredients? Acta Psychiatrica Scandinavica 113, 33-35.

Burns T., Catty J., Dash M., Roberts C., Lockwood A. \& Marshall M. (2007). Use of intensive case management to reduce time in hospital in people with severe mental illness: systematic review and metaregression. British Medical Journal 335, 336-340.

Calsyn R.J., Klinkenberg W.D., Morse G.A. \& Lemming M.R. (2006). Predictors of the working alliance in assertive community treatment. Community Mental Health Journal 42, 161-175.

Care Service Improvement Partnership, Royal College of Psychiatrists \& Social Care Institute for Excellence (2007). A Common Purpose: Recovery in Future Mental Health Services. Social Care Institute for Excellence: London.

Craig T.K., Garety P., Power P., Rahaman N., Colbert S., FornellsAmbrojo M. \& Dunn G. (2004). The Lambeth Early Onset (LEO) Team: randomised controlled trial of the effectiveness of specialised care for early psychosis. British Medical Journal 329, 1067-1070.

Dixon L.B. (2000). Assertive community treatment: twenty-five years of gold. Psychiatric Services 51, 759-765.

Drake R.E. \& Deegan P.E. (2008). Are assertive community treatment and recovery compatible? Commentary on "ACT and recovery: Integrating evidence-based practice and recovery orientation on assertive community treatment teams. Community Mental Health Joumal 44, 75-77.

Fakhoury W.K.H., White I., Priebe S. \& Plao S.G. (2007). Be good to your patient - How the therapeutic relationship in the treatment of patients admitted to assertive outreach affects rehospitalization. Joumal of Nervous and Mental Disease 195, 789-791.

Fiander M., Burns T., McHugo G.J. \& Drake R.E. (2003). Assertive community treatment across the Atlantic: comparison of model fidelity in the UK and USA. British Journal of Psychiatry 182, 248-254.

Garety P.A., Craig T.K.J., Dunn G., Fornells-Ambrojo M., Colbert S., Rahaman N., Reed J., \& Power P. (2006). Specialised care for early psychosis: symptoms, social functioning and patient satisfaction Randomised controlled trial. British Journal of Psychiatry 188, 37-45.

Glover G., Arts G. \& Babu K.S. (2006). Crisis resolution/home treatment teams and psychiatric admission rates in England. British Journal of Psychiatry 189, 441-445.

Gold P.B., Meisler N., Santos A.B., Carnemolla M.A., Williams O.H. \& Keleher J. (2006). Randomized trial of supported employment integrated with assertive community treatment for rural adults with severe mental illness. Schizophrenia Bulletin 32, 378-395.

Hoult J., Reynolds I., Charbonneau-Powis M., Coles P. \& Briggs J. (1981). A controlled study of psychiatric hospital versus community treatment - the effect on relatives. Australian and New Zealand Journal of Psychiatry 15, 323-328.

Johnson S., Nolan F., Hoult J., White I.R., Bebbington P., Sandor A., McKenzie N., Patel S.N. \& Pilling S. (2005a). Outcomes of crises before and after introduction of a crisis resolution team. British Journal of Psychiatry 187, 68-75.
Johnson S., Nolan F., Pilling S., Sandor A., Hoult J., McKenzie N., White I.R., Thompson M. \& Bebbington P. (2005b). Randomised controlled trial of acute mental health care by a crisis resolution team: the north Islington crisis study. British Medical Journal, 331, 599.

Killaspy H. (2007). Assertive community treatment in psychiatry. British Medical Journal 335, 311-312.

Killaspy H., Bebbington P., Blizard R., Johnson S., Nolan F., Pilling S. \& King M. (2006). The REACT study: randomised evaluation of assertive community treatment in north London. British Medical Journal 332, 815-818A.

Lasalvia A. \& Ruggeri M. (2007). Assessing the outcome of community-based psychiatric care: Building a feedback loop from 'real world' health services research into clinical practice. Acta Psychiatrica Scandinavica 116, 6-15

Lloyd-Evans B., Johnson S. \& Slade M. (2007). Assessing the content of mental health services: a review of measures. Social Psychiatry and Psychiatric Epidemiology 42, 673-682.

Marshall M. (2008). What have we learnt from 40 years of research on intensive case management? Epidemiologia e Psichiatria Sociale 17, 106-109.

Mezzina R. \& Vidoni D. (1995). Beyond the mental hospital: crisis intervention and continuity of care in Trieste. A four year follow-up study in a community mental health centre. International Journal of Social Psychiatry 41, 1-20.

Petersen L., Jeppesen P., Thorup A., Abel M.J., Ohlenschlaeger J., Christensen T.O., Krarup G., Jorgensen P. \& Nordentoft M. (2005). A randomised multicentre trial of integrated versus standard treatment for patients with a first episode of psychotic illness. British Medical Journal 331, 602-605.

Priebe S., Fakhoury W., Watts J., Bebbington P., Burns T., Johnson S., Muijen M., Ryrie I., White I. \& Wright C. (2003). Assertive outreach teams in London: patient characteristics and outcomes: Pan-London Assertive Outreach Study, Part 3. British Journal of Psychiatry 183, 148-154.

Rosen A., Mueser K.T. \& Teesson M. (2007). Assertive community treatment-issues from scientific and clinical literature with implications for practice. Journal of Rehabilitation Research and Development 47, 813-825.

Salvador-Carulla L., Tibaldi G., Johnson S., Scala E., Romero C. \& Munizza C. (2005). Patterns of mental health service utilisation in Italy and Spain - An investigation using the European Service Mapping Schedule. Social Psychiatry and Psychiatric Epidemiology 40, 149-159.

Salyers M.P. \& Tsemberis S. (2007). ACT and recovery: Integrating evidence-based practice and recovery orientation on assertive community treatment teams. Community Mental Health Journal 43, 619-641.

Smith L. \& Newton R. (2007). Systematic review of case management. Australian and New Zealand Journal of Psychiatry 41, 2-9.

Stein L.I. \& Test M.A. (1980). Alternative to mental hospital treatment. I. Conceptual model, treatment program, and clinical evaluation. Archives of General Psychiatry 37, 392-397.

Sytema S., Wunderink L., Bloemers W., Roorda L. \& Wiersma D. (2007). Assertive community treatment in the Netherlands: a randomized controlled trial. Acta Psychiatrica Scandinavica 116, 105-112.

Thornicroft G. \& Tansella M. (2004). Components of a modern mental health service: a pragmatic balance of community and hospital care: Overview of systematic evidence. British Journal of Psychiatry $185,283-290$.

Tyrer P. (2007). The future of specialist community teams in the care of those with severe mental illness. Epidemiologia e Psichiatria Sociale 16, 225-230.

Tyrer P., Balod A., Germanavicius A., Mcdonald A., Varadan M. \& ThomasJ. (2007). Perceptions of assertive community treatment in the UK and Lithuania. International Journal of Social Psychiatry 53, 498-506.

van Veldhuizen J.R. (2007). FACT: A Dutch version of ACT. Community Mental Health Journal 43, 421-433.

Wright C., Burns T., James P., Billings J., Johnson S., Muijen M.P.S., Ryrie I., Watts J. \& White I. (2003). Assertive outreach teams in London: Models of Operation. Pan London Assertive Outreach Study Part I. British Journal of Psychiatry 183, 132-138. 